\title{
Debates, contextos e lacunas no desenvolvimento coletivo da teoria sobre raios catódicos ${ }^{+}$
}

Defferson Rodrigues Martins das Neves ${ }^{1}$

Licenciando em Ciências - UNIFESP

São Paulo - SP

Thaís Cyrino de Mello Forato ${ }^{1}$

Universidade Federal de São Paulo

Diadema - SP

Bianca Alves Pereiral

Sabrina Alves Pereira ${ }^{1}$

Mestrandas em Ensino de Ciências e Matemática - UNIFESP

André Amaral Gonçalves Bianco ${ }^{1}$

Universidade Federal de São Paulo

Diadema - SP

\section{Resumo}

Explicações sobre experimentos científicos históricos em livros didáticos da escola básica ou livros textos de cursos superiores são comumente acompanhadas por relatos tão sucintos (e muitas vezes estereotipados) sobre o contexto da época em que esses experimentos se deram, que pouco contribuem para a compreensão do desenvolvimento científico que acompanhou o episódio. Na maioria das situações esses relatos transmitem uma visão muito simplista e presenteista de como se deu a proposição de conceitos, leis e teorias cientificas, ou sobre quais foram as influências epistêmicas e não epistêmicas na adoção de uma ou outra solução. Um exemplo clássico é o do conhecido "experimento de Thomson" sobre a constituição dos raios catódicos. Este episódio é geralmente resumido ao experimento "crucial" no qual Thomson determina o valor da relação carga/massa das partículas que constituem os raios catódicos e "descobre" o elétron, por meio das medidas das

\footnotetext{
${ }^{+}$Debates, contexts and omissions in the collective development of cathode ray theory

* Recebido: 5 de abril de 2021. Aceito: 12 de julho de 2021.

${ }^{1}$ E-mails: deffersonr@yahoo.com.br; alves-pereirabs@hotmail.com; thais.forato@unifesp.br; andrequim@yahoo.com.br
} 
deflexões elétricas e magnéticas dessas partículas. Assim, pautados nas considerações da historiografia atual das Ciências para o Ensino de Ciências e a partir da consulta em fontes primárias e secundárias sobre o tema, esse artigo procura oferecer subsidios históricos de forma a possibilitar que professores e estudantes compreendam de forma mais contextualizada aspectos da construção do conhecimento científico naquele momento histórico.

Palavras-chave: Experimento de Thomson; Experimento Histórico; Relação Carga/Massa do Elétron; História da Ciência; Ensino de Física.

\begin{abstract}
Explanations over historical scientific experiments in elementary school textbooks or textbooks from higher education courses are commonly accompanied by reports so succinct (and often stereotyped) about the context of the time when these experiments took place, which contribute little to the understanding of development scientific that accompanied the episode. In most situations, these reports convey an overly simplistic and actual view of how scientific concepts, laws and theories were proposed, or what were the epistemic and non-epistemic influences in adopting one or the other solution. A classic example is that of the well-known "Thomson's experiment" on the constitution of cathode rays. This episode is usually summarized in the "crucial" experiment in which Thomson determines the value of the charge / mass ratio of the particles that make up the cathode rays and "discovers" the electron, by measuring the electrical and magnetic deflections of these particles. Thus, based on the considerations of the current historiography of Sciences for the Teaching of Sciences and from consultation in primary and secondary sources on the subject, this article seeks to offer historical subsidies in order to enable teachers and students to understand in a more contextualized way aspects of the construction of scientific knowledge at that historic moment.
\end{abstract}

Keywords: Thomson's Experiment; Historical Experiment; Electron Charge/Mass Ratio; History of Science; Physics Teaching. 


\section{Introdução}

Muitas pesquisas (MARTINS, 2006; FORATO; MARTINS; PIETROCOLA, 2011; OLIVEIRA; DRUMMOND, 2015; MOURA; FORATO et al., 2017; VELOSO; MENDONÇA; MOZZER, 2020, etc.) indicam que ensinar disciplinas como a Biologia, a Física ou a Química por meio de abordagens pautadas na História e Filosofia das Ciências (HFC) pode favorecer aos alunos a compreensão de diferentes aspectos das Ciências e do empreendimento científico: a possibilidade de analisar o passado em seus próprios termos (MARTINS, 2001), refletir sobre a prática científica (JARDIM; GUERRA, 2017), conhecer correntes filosóficas, o contexto econômico, político e social e sua influência nas decisões e modo de pensar dos pesquisadores em determinado momento histórico (BRAGA; GUERRA; REIS, 2012), reduzir a crença em pseudo-histórias e em personagens míticos (ALLCHIN, 2004), compreender o papel dos experimentos no desenvolvimento das Ciências (MEDEIROS; MONTEIRO, 2001), possibilitar reflexões críticas sobre episódios históricos apresentados no Ensino de Ciências (FORATO; MARTINS; PIETROCOLA, 2011), colocar os professores em formação em contato com as ideias da historiografia das Ciências (SCHMIEDECKE; PORTO, 2014) e compreender conceitos científicos, entre outros.

Ainda assim, alguns pesquisadores alertam para a existência de algumas dificuldades ou obstáculos para a inserção da abordagem histórica das Ciências em sala de aula (MARTINS, 2007; FORATO et al., 2012; OLIVEIRA; DRUMMOND, 2015; HIDALGO et al., 2018), por exemplo: i) abordagens simplistas de episódios históricos em livros didáticos e materiais de divulgação científica; ii) falta de preparo dos professores; iii) inadequação dos textos utilizados; iv) relação entre a extensão e a profundidade dos assuntos; v) falta de material pedagógico adequado; vi) a resistência dos alunos e da escola; entre outros.

Martins (2007) elenca alguns dos principais obstáculos para o trabalho com a HFC no Ensino de Ciências, figurando, principalmente, "a falta de material didático adequado". Dentre as demais dificuldades citadas pela literatura compreendemos que o preparo inadequado ou insuficiente de professores também possui uma relevante importância (FORATO, 2009) uma vez que essa situação tende a contribuir para a tímida adesão de propostas de ensino pautadas na HFC (OLIVEIRA; DRUMMOND, 2015).

Motivado por essas considerações, este trabalho apresenta uma proposta de abordagem crítica e contextualizada, sob a perspectiva histórica, sobre os experimentos com raios catódicos, desenvolvidos ao final do século XIX. O texto resultante e a apresentação da metodologia para a sua produção se propõem, tanto a reduzir a falta de material didático adequado à inserção da HFC no Ensino de Ciências, como contribuir para uma melhor preparação dos professores de Ciências para a utilização de abordagens pautadas na HFC.

Os experimentos realizados por Joseph John Thomson (1856-1940) sobre as partículas constituintes dos raios catódicos representam um momento relevante na História das Ciências, discutido nos cursos de Licenciatura e Bacharelado em Física ou Química, bem como nas referidas disciplinas no Ensino Médio. Esse episódio histórico envolve conceitos 
científicos fundamentais para os modelos de constituição da matéria que aceitamos hoje, além de exemplificar aspectos epistêmicos e não epistêmicos do desenvolvimento das Ciências. Ademais, em oposição ao enaltecimento de um único personagem, o episódio revela outras pessoas e diferentes contribuições para a elaboração desses saberes teóricos e experimentais.

É importante trazer a essa contextualização que a revisão sistemática realizada por Teixeira, Greca e Freire (2012) aponta que tópicos de Física Moderna e Contemporânea estão entre os menos presentes na linha HFC no Ensino, e o episódio histórico aqui proposto pode ser um interessante recurso para introduzir tais conteúdos.

Em um trabalho anterior, desenvolvemos uma adaptação experimental para a medição da relação carga/massa das partículas constituintes dos raios catódicos, com a utilização de materiais de custo relativamente baixo; a elaboração de uma solução para o cálculo da relação carga/massa, adequada às diferentes medidas propostas por aquela adaptação; e a apresentação dos benefícios pedagógicos e formativos do estudo dos fenômenos físicos envolvidos, da resolução de problemas durante a confecção do experimento e da medição de algumas grandezas físicas durante a utilização do equipamento (Neves et al., 2019). O texto histórico, resultado desta pesquisa, oferece subsídios para uma abordagem mais bem circunstanciada sobre o contexto socio-científico e os aspectos da Natureza das Ciências (NDC) que permeavam o ambiente de desenvolvimento do referido experimento.

A partir de embasamento na historiografia contemporânea (MARTINS, 2001; 2010) e utilizando fontes primárias e secundárias, concebemos um recorte histórico, apresentando aspectos da construção sócio-histórica da ciência, contextualizando alguns dos conceitos físicos (FORATO, 2009) e que permite, também, a compreensão de técnicas experimentais empregadas naquela época (SAITO, 2014).

Dentre outros aspectos da NDC, as fontes primárias trazem fortes indícios do caráter coletivo e não linear da ciência na época, e indicam possibilidades que favorecem a compreensão de conceitos físicos presentes nos aparatos experimentais. Já as fontes secundárias permitiram uma ampla reflexão sobre possíveis causas para a supervalorização de um personagem histórico em detrimento de outros.

Contudo, a contextualização social e cultural dos eventos históricos não se configura uma tarefa fácil, sendo necessário considerar recomendações da historiografia contemporânea, como a perspectiva discutida por Martins (2001), que pressupõe considerar o passado em seus próprios termos, confrontar diferentes visões especializadas etc. Nesse sentido, este trabalho procurou seguir também orientações elaboradas por Martins (2005), procurando utilizar uma terminologia adequada à HFC, discutindo as contribuições dos pesquisadores dentro do seu próprio contexto científico, delimitando o recorte a um nível que pudesse ser pesquisado com certa profundidade e que, ao mesmo tempo, fosse interessante para o público-alvo e escolhendo um tema afeto a uma área das Ciências Naturais que fosse familiar aos autores.

Buscamos destacar a omissão de diversos aspectos nas fontes primárias e secundárias que localizamos, que oferecem diferentes reflexões, por exemplo, a inexistência de mulheres 
mencionadas ou autoras de pesquisas nos temas em questão; a ausência de crédito aos auxiliares dos diferentes laboratórios e pesquisadores envolvidos no experimento; e poucas reflexões sobre o contexto social político ou econômico que poderiam ter motivado essas pesquisas. Apesar do compromisso historiográfico com o recorte (MARTINS, 2004), os diferentes silêncios constituem-se fonte de reflexão para o estudo do episódio.

Após uma breve fundamentação sobre os usos da HFC no ensino, apresentamos a metodologia utilizada para a construção de uma abordagem histórica para o ambiente educacional e depois, nosso resultado, o relato histórico sobre o episódio considerado.

\section{História das Ciências no Ensino de Ciências}

Braga, Guerra e Reis (2012) defendem que, para além dos conteúdos específicos de cada área do conhecimento científico, deve-se aprender competências e habilidades acerca dos processos de construção do conhecimento e indicam que a HFC pode contribuir de forma pontual para o aprendizado sobre a NDC.

A análise de recortes históricos, a partir das fontes selecionadas e dos objetivos que guiam a interpretação, permite exemplificar diferentes aspectos da NDC (MARTINS, 2004). Nossa análise permitiu, por exemplo, perceber as seguintes dimensões: i) a Ciência não é definitiva e descoberta por gênios que não erram, é, na verdade, construída por seres humanos falíveis, num esforço conjunto e está em constante mudança (MARTINS, 2006); ii) não se deve inferir que o insucesso de cientistas desconhecidos foi resultado de uma pesquisa fracassada, em oposição à escolha de um método correto por parte daqueles que se tornaram famosos (ALLCHIN, 2004); e iii) experimentos que marcaram uma determinada época não puderam ser realizados e compreendidos sem um conhecimento prévio da teoria que os direcionava (KUHN, 2013 [1962]).

Ademais, Peter Heering (2014, p. 145) aponta que uma análise da situação histórica pode evidenciar a equivocada concepção de que alguns experimentos são tão fáceis de realizar que "apenas um experimentador incompetente pode produzir um resultado errôneo". Ainda de acordo com este autor, considerações históricas de experimentos científicos podem demonstrar que uma solução tida como "engenhosa e particularmente simples" não seria viável sem o conhecimento implícito a respeito do fenômeno estudado, o controle de influências externas, um suporte matemático adequado e a necessidade de habilidades particulares, entre outros.

É relevante lembrar que a atividade do historiador das ciências é também influenciada por seu contexto pessoal e social. Conforme a análise realizada em um determinado recorte histórico, diferentes aspectos da NDC serão explicitados, em função das fontes selecionadas, das hipóteses de pesquisa do historiador, das relações que ele estabelecerá entre as personagens, ou ainda de outros aspectos epistêmicos e os não epistêmicos que serão considerados (MARTINS, 2010). Um historiador das Ciências pode estar interessado em analisar as técnicas experimentais utilizadas, ou as diferentes concepções 
teóricas que fundamentavam as diferentes teorias, ou relações políticas entre grupos de pesquisa etc. As diferentes análises sobre o passado trazem uma rica diversidade de exemplos sobre a NDC. Com isso, entendemos que as diferentes listas de aspectos da NDC, que constam em pesquisas recentes, podem ser entendidas como exemplos de NDC, e não um retrato essencialista, ou reducionista, que pretenderia descrever o que a Ciência é. A partir de um recorte histórico é possível propor os aspectos da NDC que poderão ser abordados no ensino, evitando sugerir aspectos essencialistas que desconsideram a pluralidade metodológica das ciências (FORATO; BAGDONAS; TESTONI, 2017).

Ao se abordar aspectos do desenvolvimento científico nas aulas de Ciências, é comum presenciarmos discursos que destacam como importantes personalidades os homens, brancos e geralmente de origem europeia, invisibilizando a presença e as contribuições de mulheres, de negros e de povos de outras regiões (LIMA, 2019; PINHEIRO, 2020). Lima (2019) ressalta a escassez de trabalhos que problematizem a questão do papel da mulher no desenvolvimento científico, tanto em eventos relacionados ao ensino de Física, como nos principais periódicos que publicam os resultados das pesquisas da área. Propomos que destacar a ausência de tais temas nas fontes históricas permite aos docentes trazerem à tona a reflexão e a discussão da temática.

\section{Construindo abordagem histórica para o ambiente escolar: apoio metodológico}

A elaboração desta contextualização histórica sobre o experimento de Thomson foi realizada a partir da pesquisa bibliográfica e estudo de fontes históricas, e de uma análise que fundamentou a construção dessa abordagem didática para o Ensino de Ciências.

A metodologia de pesquisa sobre o episódio histórico consistiu na revisão bibliográfica de fontes primárias e fontes secundárias, pautada na historiografia contemporânea (D’AMBRÓSIO, 2004; DEBUS, 2004; KUHN, 2013 [1962]; MARTINS, 2001; 2004; MARTINS, 2005). Selecionamos fontes secundárias de diferentes períodos, para conhecermos diferentes olhares e interpretações do recorte histórico (ACHISTEIN, 2001; CHALMERS, 1949; FALCONER, 2001; GOODAY, 2001; SCHWARTZ; BISHOP, 1958; SMITH, 2001; TOWNSEND, 1915; WHITTAKER, 2012 [1910]) e auxiliar em nossa leitura das próprias fontes primárias (PERRIN, 1896; THOMSON, 1958 [1897]; THOMSON, 2012 [1903]).

A elaboração da narrativa histórico-pedagógica sobre o recorte histórico ${ }^{2}$ foi fundamentada pelos parâmetros para a transposição didática da história e natureza das ciências para o ensino de ciências (FORATO, 2009). Esse referencial auxiliou na delimitação e enfoque do recorte histórico, a partir da consistência entre os objetivos pedagógicos visados

\footnotetext{
2 Importa esclarecer que usamos a terminologia "narrativa histórico-pedagógica" por se tratar de uma narrativa histórica voltada ao Ensino de Ciências e para diferenciar de uma pesquisa original em história das ciências voltada para historiadores. O referencial adotado (Forato, 2009) volta-se a apoiar a criação de narrativas históricas didáticas para o Ensino de Ciências e ambientes educacionais afins.
} 
e o ambiente escolar para o qual a narrativa histórica é proposta, quais sejam, diferentes disciplinas na formação de professores de física, química e áreas afins, abordando explicitamente e de maneira contextualizada algumas práticas e conceitos científicos, como oportunidade para trazer a dimensão cultural e social das ciências, envolvidas no desenvolvimento científico.

Os quadros de 1 a 4 abaixo, agrupam os parâmetros que suscitaram as reflexões, ponderações e análises do conteúdo histórico para compor a narrativa histórica. A coluna da esquerda comunica o que se pretende com cada conjunto de reflexões, enquanto a coluna da direita apresenta os parâmetros adaptados a partir de Forato (2009, v. 1, p. 183-196). Abaixo de cada quadro, consta breve síntese das reflexões que eles suscitaram.

Quadro 1: Objetivos da abordagem histórica.

\begin{tabular}{|l|l|}
\hline ADEQUANDO AO AMBIENTE ESCOLAR & PARÂMETROS PARA REFLEXÃO E ANÁLISE \\
\hline - Estabelecer os objetivos pedagógicos sobre & - Estabelecer os propósitos pedagógicos para o \\
$\begin{array}{l}\text { conteúdos científicos, epistêmicos e não } \\
\text { epistêmicos a serem tratados, assim como } \\
\text { propósitos formativos. }\end{array}$ & - Explicitar os aspectos da NDC pretendidos. \\
\hline
\end{tabular}

Fonte: Adaptado a partir de Forato (2009, v. 1, p. 183-196).

Esses dois primeiros parâmetros estabelecem o ponto de partida para a didatização do episódio, considerando quais conceitos científicos podem ser evidenciados e que aspectos da NDC se busca explicitar, a partir de cada contexto educacional. Do nosso ponto de vista, a abordagem contextualizada dos experimentos sobre a constituição dos raios catódicos pode beneficiar:

i) a compreensão de conceitos científicos tais como: carga, campo e força elétricos e magnéticos, potencial elétrico, energia cinética, conservação de energia entre outros;

ii) a discussão dos seguintes aspectos da NDC: os problemas científicos que motivaram os experimentos; as colaborações e desacordos entre os cientistas; o desenvolvimento não linear e não cumulativo da ciência; o papel dos erros na construção da ciência em oposição à ideia dos gênios infalíveis; como as observações são influenciadas teoricamente; a inexistência de um único método experimental; a influência de concepções metafísicas na aceitação de teorias; e a influência do prestígio de um pesquisador na aceitação de sua teoria;

iii) a reflexão sobre a ausência de mulheres e auxiliares de laboratórios nas fontes históricas, reduzindo as Ciências como um constructo exclusivo de uma elite masculina.

Pode-se ainda suscitar outros objetivos formativos, por exemplo, aprimorar a capacidade leitora e a interpretação de artigos científicos e propor aos estudantes o exercício de desenvolver atividades para a escola básica, a partir dessa abordagem histórica. Ademais, a abordagem contextualizada da atividade científica é considerada como requisito fundamental 
para a alfabetização científica (SASSERON; CARVALHO, 2011), e para a promoção de direitos humanos (OLIVEIRA; DRUMMOND, 2015).

Quadro 2: Definindo o recorte e o enfoque para o episódio histórico.

\begin{tabular}{|l|l|}
\hline ADEQUANDO AO AMBIENTE ESCOLAR & PARÂMETROS PARA REFLEXÃO E ANÁLISE \\
\hline - Buscar coerência entre a visão de NDC & - Selecionar o tema e o(s) episódio(s) históricos \\
pretendida e o relato histórico construído. & apropriados aos objetivos estabelecidos acima. \\
- Evitar que a concepção de ciência enquanto & - Selecionar os aspectos a enfatizar e a omitir \\
constructo sócio-histórico, valorize em demasia & nos conteúdos do recorte histórico. \\
aspectos subjetivos, e negligencie a relevância & - Confrontar os aspectos omitidos com a visão \\
de parâmetros objetivos na ciência, levando à & de NDC objetivada. \\
um relativismo ingênuo. & - Definir o nível de detalhamento do contexto \\
& $\begin{array}{l}\text { não científico ou não epistêmico a ser tratado, } \\
\text { buscando evitar promover interpretações } \\
\text { relativistas extremas. }\end{array}$ \\
\hline
\end{tabular}

Fonte: Adaptado a partir de Forato (2009, v. 1, p. 183-196).

O tema do episódio volta-se aos experimentos realizados no final do século XIX, para estudar a natureza dos raios catódicos. Concentramo-nos sobre os experimentos que buscavam determinar a relação carga/massa das partículas constituintes dos raios catódicos, mais especificamente, os realizados por J. J. Thomson, na última década daquele século. A escolha por este recorte se deu pela abordagem simplista com que a presumida "descoberta do elétron" é comumente realizada no ensino de Física e Química. Na literatura consultada são apresentados alguns aspectos que mostram a coletividade na ciência, os desacordos, os erros, as concepções teóricas que influenciaram a observação dos experimentos. Destacando as diferentes explicações contemporâneas, bem fundamentadas por distintos modelos teóricos, busca-se mostrar o desenvolvimento não-linear da ciência. A variedade de caminhos e de propostas para realizar os inúmeros experimentos, permite problematizar a ideia de um único método científico. Enfatiza-se, ainda, que a aceitação ou rejeição das entidades metafísicas no contexto cultural específico interferiu no reconhecimento, ou não, de alguns pesquisadores.

Qualquer recorte histórico é amplo e permeado por inúmeros aspectos epistêmicos e não epistêmicos. Há muitos pesquisadores e estudiosos que não foram sequer mencionados pela literatura consultada e outros que foram citados, mas não foram objeto de nossa análise. Entretanto, alguns conteúdos podem ter uma conexão evidente com o recorte estabelecido, mas foram omitidos em função dos objetivos buscados e do tempo adequado para a proposta pedagógica. Nesta proposta, por exemplo, foram omitidos os estudos a respeito dos raios $\mathrm{x}^{3} \mathrm{e}$

\footnotetext{
3 Importa esclarecer que a prática científica da época, assim como a dos dias atuais, não se justificava por si só. Um exemplo da aplicação de resultados obtidos em pesquisas de laboratório sobre os raios catódicos foi a descoberta dos raios $\mathrm{x}$, que motivado pela sua utilização na radiografia de partes do corpo humano, teve um rápido avanço nas pesquisas sobre sua produção (MARTINS, 2012a).
} 
da radioatividade, que foram realizados no mesmo período, como desdobramento dos experimentos com descargas elétricas em gases rarefeitos. Não são discutidas também, outras teorias consideradas à época, como a defendida por Crookes e Schuster, sobre os raios catódicos resultarem da ionização do gás residual no interior do tubo de descargas. Não são tratadas as questões econômicas envolvidas nesses estudos, assim como as crenças pessoais ou ideológicas dos cientistas, pois tais omissões não prejudicam nossos objetivos. Embora tais aspectos omitidos pudessem trazer interessantes discussões epistemicas, é necessário delimitar o tempo didático para intelecção do tema. Os aspectos selecionados são suficientes para contextualizar conceitos de física frente aos resultados experimentais e a concepção de NDC pretendida, ou seja, nossos objetivos pedagógicos.

A influência do prestígio de Thomson para o reconhecimento e divulgação de seus resultados é um aspecto da prática científica que pode ser considerado como não epistêmico. Buscando evitar o risco de sobrevalorizar um subjetivismo e concepções relativistas extremas, o relato histórico enfatiza aspectos experimentais e matemáticos na realização dos experimentos. O risco de um relativismo ingênuo, quando se problematiza a ideia de verdades finais, de neutralidade, de um único método científico e da pura objetividade na ciência pode ser compensado pela apresentação de critérios científicos compactuados pela comunidade da época, como, por exemplo, a observação criteriosa, a experimentação reprodutível, a matematização de resultados, o teste de hipóteses mediante a pluralidade metodológica aceita pela comunidade científica de cada época e local (FORATO, 2009, capítulo 2).

Quadro 3: Problematizando estereótipos, mitos e preconceitos.

\begin{tabular}{|c|c|}
\hline & \\
\hline $\begin{array}{l}\text { - Estabelecer relação entre resultados relevantes } \\
\text { para a construção da ciência com conteúdos } \\
\text { descartados ou atualmente considerados } \\
\text { "esquisitos", como contraponto ao } \\
\text { presenteísmo. } \\
\text { - Apresentar vários pensadores contemporâneos } \\
\text { trabalhando com os mesmos pressupostos } \\
\text { metodológicos pode auxiliar na crítica ao }\end{array}$ & $\begin{array}{l}\text { nicamente os conteúdos da } \mathrm{HC} \\
\text { ensão atualmente. } \\
\text { diacronicamente diferentes } \\
\text { ciência e o pensamento dos } \\
\text { fos naturais e cientistas de } \\
\text { e civilizações. } \\
\text { mplos de teorias superadas em } \\
\text { xtos culturais permite criticar } \\
\text { sobre história e epistemologia } \\
\text { a possível concepção de que a }\end{array}$ \\
\hline
\end{tabular}

Fonte: Adaptado a partir de Forato (2009, v. 1, p. 183-196).

É comum encontrarmos narrativas em materiais didáticos atribuindo a "descoberta" do elétron exclusivamente a Thomson. Essa forma de explorar o tema fomenta o estereótipo do gênio isolado e visões ingênuas sobre a NDC. Problematizamos essa visão trazendo as contribuições de outros pensadores para interpretar o fenômeno, assim como mostramos 
visões aceitas e pertinentes para a época. Algumas ideias de pesquisadores da época podem parecer estranhas ao estudante. Por exemplo, a ideia de que os raios catódicos eram perturbações do éter, um ente metafísico não aceito pela ciência atual, é geralmente desconhecida no ambiente escolar. Do mesmo modo, as ideias sobre uma luz magnética podem ser esquisitas, atualmente (JAUNCEY apud MARTINS, 2012a). Quando se mostra aos estudantes que diferentes concepções foram descartadas, mas eram plausíveis e bem fundamentadas em sua época, pode-se discutir o caráter provisório das teorias e a não linearidade na ciência. Há ainda outras hipóteses descartadas que foram importantes para o desenvolvimento das Ciências, por exemplo: as experiências que tentavam desviar os raios catódicos ao atravessarem uma região com campo elétrico formado entre placas eletrizadas com cargas opostas. Como isso não ocorria, o argumento de que os raios catódicos seriam partículas com algum tipo de carga era fragilizado. No entanto, o aprimoramento das bombas a vácuo permitiu que tal concepção fosse refutada, sendo fundamental para o prosseguimento das pesquisas.

Em síntese, mostrar aos estudantes que existiram diferentes teorias, experimentos que deram errados e ideias que foram descartadas pode promover a reflexão sobre os aspectos da NDC pretendidos, como problematizar a questão dos gênios infalíveis e de um único método experimental. Embora o éter tenha sido um ente não detectável e excluído da ciência atual, ele fundamentou várias teorias ao longo do século XIX e promoveu o desenvolvimento de vários conceitos que aceitamos até hoje (MARTINS, 2006).

Quadro 4: Pensando a construção de textos para professores e estudantes.

\begin{tabular}{|c|c|}
\hline ADEQUANDO AO AMBIENTE ESCOLAR & PARÂMETROS PARA REFLEXÃO E ANÁLISE \\
\hline $\begin{array}{l}\text { - Atividades didáticas podem utilizar debates } \\
\text { entre teorias, explorar controvérsias na ciência, } \\
\text { enfatizar a pluralidade metodológica, a } \\
\text { coletividade, os erros, os problemas que } \\
\text { originaram ideias e mostrar a limitação das } \\
\text { teorias sobre aspectos ainda em aberto. } \\
\text { - Evitar juízos de valor, afirmações absolutas, } \\
\text { pretensão ingênua de estar "varrendo" toda uma } \\
\text { época ou tema. } \\
\text { - O texto histórico pode trazer pautas atuais e } \\
\text { importantes, por exemplo, ao denunciar a } \\
\text { ausência de mulheres e auxiliares } \\
\text { invisibilizados pela historiografia que enaltece } \\
\text { o estereótipo da ciência elitista, branca, } \\
\text { masculina e individual. }\end{array}$ & $\begin{array}{l}\text { - Ponderar sobre o uso de fontes primárias na } \\
\text { escola básica: se, quando, quanto e como } \\
\text { introduzi-las. Importante recorrer ao apoio de } \\
\text { fontes secundárias especializadas. } \\
\text { - Definir o nível de profundidade e formulação } \\
\text { discursiva dos conteúdos metafísicos ou não } \\
\text { epistêmicos. } \\
\text { - Ponderar sobre a quantidade e profundidade } \\
\text { dos textos históricos para cada contexto } \\
\text { educacional. } \\
\text { - Defender uma nova ideia conflitante com } \\
\text { aquelas predominantes no repertório cultural } \\
\text { dos estudantes requer o uso de estratégias } \\
\text { capazes de criar desconforto, conflitos que } \\
\text { permitam a reflexão sobre visões e crenças } \\
\text { preestabelecidas sobre as ciências. } \\
\text { - Ter em mente as diferentes funções sociais do } \\
\text { conhecimento acadêmico e dos saberes }\end{array}$ \\
\hline
\end{tabular}




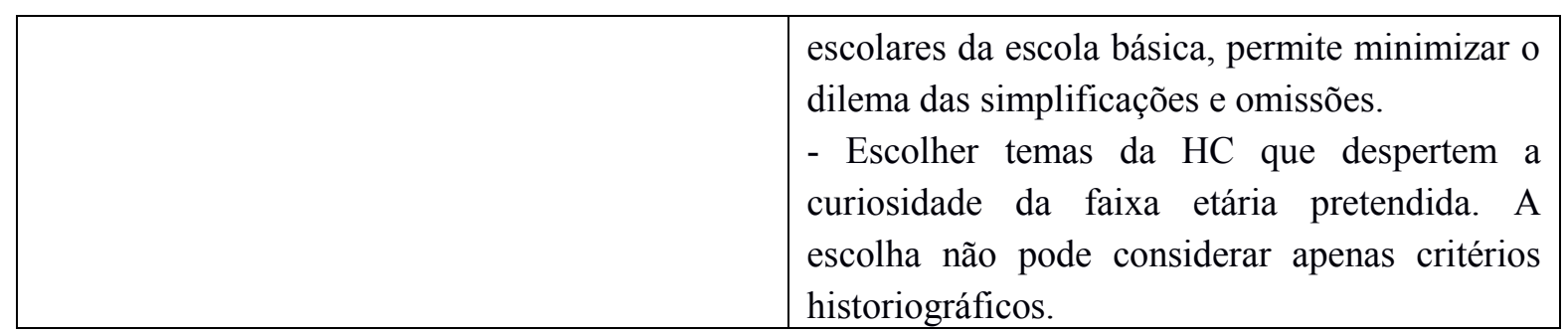

Fonte: Adaptado a partir de Forato (2009, v. 1, p. 183-196).

A narrativa histórico-pedagógica foi escrita para o ambiente da formação inicial e/ou continuada de professores, contudo, pode também ser adaptado e utilizado com alunos do Ensino Médio. É desejável que os professores tenham contato com, pelo menos, alguns trechos de fonte primária. Para esse estudo, tais fontes primárias foram estudadas com o auxílio de trabalhos especializados, fontes secundárias escritas por historiadores das ciências. Pequenos trechos dos originais foram introduzidos no texto, mas sempre com o apoio de uma interpretação especializada, à luz do seu tempo.

Por se tratar da formação de professores, não se espera que haja dificuldades para interpretar o vocabulário especializado, os conceitos, as matematizações, inclusive os conteúdos metafísicos. Em outras palavras, estamos considerando que a quantidade e profundidade do texto seja adequada para o ambiente educacional da formação de professores. Consideramos ainda, que este artigo oferece não apenas uma abordagem histórica relevante para a formação de professores, mas que seus aspectos teórico-metodológicos explicitados podem servir como base para outros trabalhos nas mesmas áreas de pesquisa.

Entender os conflitos entre as visões de diferentes pesquisadores sobre a natureza dos raios catódicos permite problematizar a crença em uma concepção definitiva da existência material do elétron, enquanto uma partícula, provavelmente presente no repertório cultural dos nossos estudantes. Mesmo com o experimento de Thomson, considerado por muitos como crucial, algumas dúvidas ainda prevaleciam entre alguns cientistas da época.

Sobre as funções sociais do conhecimento acadêmico e dos saberes escolares da escola básica, importa reafirmar que o texto não é escrito para o âmbito da pesquisa original em história da ciência, mas sim para o ambiente escolar da formação de professores e áreas afins e pode ser adaptado para a escola básica. Os obstáculos e desafios previstos nessa mudança de nicho epistemológico foram analisados no referencial que apoia esta análise (FORATO, 2009). Nesse sentido, propomos que as omissões também se constituem conteúdo relevante, pois suscitam reflexões sobre a ausência de contribuições de pesquisadores de outras nacionalidades, de mulheres, de pesquisadores auxiliares, técnicos e ajudantes do laboratório, problematizando a visão de uma história das ciências eurocêntrica, que apagou a apropriação de saberes produzidos por outras culturas. Ademais, é importante relembrar que todo estudo e enfoque de um episódio histórico é também uma atividade humana e sempre está restrito a um recorte, que omite inúmeras personagens e questões contextuais, e irá fomentar uma visão sobre a ciência e sua natureza (MARTINS, 2004). Daí a importância de 
professores saberem identificar os objetivos implícitos e explícitos em toda narrativa histórica (FORATO, 2013).

Com relação à motivação dos alunos, a concepção de matéria resultante do conhecimento advindo dos experimentos sobre raios catódicos é um tema relevante na formação de professores e item do currículo da Química e da Física.

\section{Uma proposta de abordagem histórica para os experimentos sobre a relação carga/massa das partículas constituintes dos raios catódicos}

No final do século XIX, havia um grande otimismo com o desenvolvimento técnico e científico. As máquinas a vapor foram aperfeiçoadas e aplicadas aos transportes, em navios, trens e automóveis. Surgiram grandes usinas para a geração de eletricidade e as lâmpadas elétricas começaram a substituir a iluminação com lampiões e com gás. A fotografia havia sido desenvolvida e, a partir dela, os primórdios do cinema. Surgiu o telefone, e logo se tornou possível fazer ligações interurbanas. Além disso, foram estendidos cabos de telégrafo através do oceano Atlântico, para comunicação intercontinental. Na comunidade científica, em 1900, o físico escocês William Thomson, Lorde Kelvin (1824-1907), chegou a afirmar que sentia pena dos jovens físicos, pois as teorias fundamentais da Física já estavam prontas e nada de emocionante restava para pesquisar (MARTINS, 2008). Hoje, sabemos que Lorde Kelvin estava enganado, mas é nesse clima de euforia e progresso que Joseph John Thomson e outros pesquisadores realizam seus estudos sobre os raios catódicos.

J. J. Thomson nasceu em Cheetham Hill, Reino Unido, em 18 de dezembro de 1856 e faleceu em 30 de agosto de 1940, em Cambridge. Iniciou sua vida acadêmica em Manchester, aos 14 anos, ao ingressar no Owen's College (atual Universidade de Manchester) para cursar engenharia, e prosseguiu seus estudos no Trinity College (um anexo à Universidade de Cambridge). Chefiou o laboratório Cavendish de física experimental (1884-1919) assumindo a presidência da Royal Society, no período de 1915 a 1920. Thomson desenvolveu grande interesse pelas teorias atômicas da matéria de John Dalton (1766-1844) e, em 1906, recebeu o Prêmio Nobel de física em reconhecimento aos méritos de suas investigações teóricas e experimentais sobre a condução de eletricidade em gases. Mas, ainda antes disso, em 1897, em seu trabalho sobre raios catódicos, Thomson postulou que todos os elementos químicos seriam formados por um constituinte universal com uma massa mil vezes menor que a massa conhecida para o átomo de hidrogênio (LOPES; MARTINS, 2009). Esse episódio costuma ser conhecido como a "descoberta do elétron".

Buscaremos criticar essa visão, apresentando um pequeno exemplo de outras pesquisas sendo realizadas à época, dentre um universo ainda maior, e de desacordos entre cientistas, além de problematizar uma concepção de verdade sobre a natureza do elétron.

Mas, do que seriam compostos esses tais raios catódicos?

O experimento de Thomson que teria conduzido à "descoberta do elétron" é geralmente descrito de modo bem simplificado: na Fig. 1 temos a representação mais comum 
do aparato experimental utilizado, composto por um tubo de raios catódicos, um par de bobinas paralelas, uma fonte de alta tensão contínua e uma fonte de baixa tensão contínua (as fontes não estão representadas na figura). Com o auxílio de uma bomba de vácuo tentava-se extrair o máximo de ar ou qualquer outro gás do interior dos tubos e depois o mesmo era vedado. No interior desses tubos havia o cátodo, o ânodo e duas placas metálicas paralelas. $\mathrm{O}$ cátodo e o ânodo eram ligados externamente aos polos negativo e positivo, respectivamente, de uma fonte de alta tensão e as placas paralelas eram ligadas à fonte de baixa tensão. Aplicando-se uma diferença de potencial da ordem de 2000 Volts entre eles, surgia um "raio" luminoso que percorria uma trajetória retilínea entre ambos, e como havia uma fenda no ânodo, os raios o atravessavam e se chocavam com a "parede" na outra extremidade do tubo.

Nos experimentos realizados naquela época, percebeu-se que estes raios deflexionavam (ou seja, mudavam sua trajetória) ao serem expostos a campos magnéticos (gerados pelas bobinas quando ligadas a uma fonte de tensão contínua e percorridas por uma corrente elétrica) ou a campos elétricos (gerados pelas placas metálicas paralelas quando ligadas à fonte de tensão).

Esses fenômenos causavam muitos questionamentos a aqueles que tentavam entender a natureza dos raios catódicos: seriam estes raios algum tipo de luz? Seriam compostos por minúsculas partículas? Seriam uma perturbação no éter? Possuiriam alguma carga elétrica?

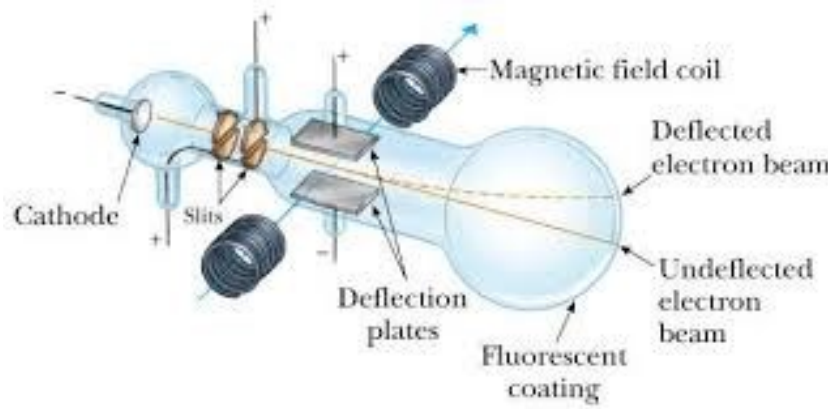

Fig. 1 -Imagem representativa do aparato utilizado por Thomson. Fonte: SERWAY; JEWETT, 2014.

Tais perguntas foram sendo respondidas a partir das contribuições de diferentes pesquisadores de distintas áreas do conhecimento. No final do século XIX, havia duas hipóteses mais debatidas pelos cientistas que se propunham a explicar a natureza dos raios catódicos, além de outras menos conhecidas, como a de Sir Franz Arthur Friedrich Schuster (1851-1934), mencionada oportunamente.

Uma primeira hipótese, defendida por físicos que pensavam como Eugen Goldstein (1850-1930), Heinrich Rudolf Hertz (1857-1894) e Philipp Eduard Anton von Lenard (18621947), considerava que este fenômeno seria como a luz, devido à vibrações do éter, ou ainda, 
que os raios fossem luz de um curto comprimento de onda. ${ }^{4}$ Essa hipótese era facilmente compreendida e coerente com os pressupostos da comunidade científica da época, já que tais raios percorriam um caminho retilíneo, excitavam a fosforescência em alguns materiais e sensibilizavam placas fotográficas (PERRIN, 1896).

Uma segunda hipótese, apoiada por aqueles que seguiam as ideias de Sir Willian Crookes (1832-1919) e J. J. Thomson, considerava que esses raios eram formados por matéria, com uma carga negativa e se movendo a altas velocidades. O que poderia ser prontamente explicado pelas suas propriedades mecânicas e pelo fato de se tornarem curvos quando submetidos a um campo magnético (PERRIN, 1896).

Hertz estava entre os muitos cientistas contrários à hipótese de que os raios catódicos teriam uma natureza corpuscular. Ele tinha como argumento contrário à hipótese das partículas carregadas o fato de que, até então, não havia sido verificada a produção de nenhuma força elétrica ou magnética a partir das mesmas. E ainda, apresentava outra justificativa, o fato de que essas partículas não eram afetadas por uma força eletrostática externa de baixa intensidade, como pôde inferir em seus experimentos de 1883 (WHITTAKER, 2012 [1910]).

Outro importante fenômeno observado por Hertz e contrário à hipótese das partículas carregadas era o fato de que os raios catódicos eram capazes de atravessar filmes metálicos muito finos, de ouro ou alumínio, mas opacos o suficiente para impedir que a luz os atravessasse (CHALMERS, 1949; HERTZ apud MARTINS, 2012a). Como a mais diminuta partícula poderia atravessar um filme metálico por mais fino que fosse? Uma questão intrigante para a época.

Um aluno de Hertz, Lenard, reforçou a hipótese da impossibilidade de as partículas atravessarem a mais fina película, quando em 1894, acrescentou uma "janela" em uma das extremidades do tubo de descargas, do lado oposto ao cátodo, cobrindo a mesma com uma fina camada de alumínio. Com isso, ele observou que os raios, além de atravessarem essa fina camada de alumínio para o exterior do tubo, ainda penetravam por alguns centímetros no ar (THOMSON, 1958 [1897]). Fato que, para Lenard, era um contrassenso, pois, de acordo com a teoria da dinâmica dos gases, se os raios fossem compostos por partículas, estas sofreriam tantas colisões com as partículas do ar que sua atividade cessaria a milímetros de distância fora do tubo (CHALMERS, 1949).

Lenard percebeu ainda que os efeitos dos raios catódicos ocorriam a distâncias de até 30 centímetros além dos limites dos tubos de descarga, como por exemplo, sensibilizando chapas fotográficas e descarregando eletroscópios. A esse respeito, Martins (2012a, p. 24)

\footnotetext{
4 Desde os anos 1820, principalmente a partir dos trabalhos de Thomas Young e Agustin Fresnel, a maioria da comunidade científica europeia aceitava a luz como uma vibração no éter luminífero. O éter era considerado por Agustin Jean Fresnel (1788-1827) como um meio material extremamente sutil, que seria mais denso dentro dos corpos transparentes, e que preencheria todos os espaços vazios do universo. A luz seria uma vibração que se propaga nesse éter. Além da luz, o éter foi utilizado para explicar outros fenômenos físicos ao longo do século XIX, como o calor, a eletricidade e o magnetismo, entre outros (MARTINS, 2012b).
} 
observa que "É provável que Lenard estivesse na verdade observando o efeito de Raios $X$, mas ele não investigou o fenômeno" 5 .

Resumindo os principais argumentos apresentados até agora para defender os raios catódicos como perturbações no éter (luz), temos que tais raios percorriam um caminho retilíneo, excitavam a fosforescência em alguns materiais e sensibilizavam placas fotográficas. Ademais, o éter era aceito na época e utilizado para explicar outros fenômenos físicos. Havia ainda argumentos para refutar a hipótese dos raios catódicos como partículas:

a) eles não exerciam forças elétricas ou magnéticas;

b) não eram afetados por uma força eletrostática externa de baixa intensidade;

c) eram capazes de atravessar películas finas de ouro ou alumínio;

d) seus efeitos podiam ser percebidos até 30 centímetros no ar, ao emergirem do tubo.

Perrin conhecia as diferentes hipóteses que orientavam as pesquisas sobre raios catódicos na época e os argumentos que seus apoiadores utilizavam para defendê-las. Os desvios causados por campos magnéticos eram tidos como um forte indício da característica negativa (carga) dos raios catódicos pelos defensores da hipótese corpuscular. Os contrários à essa hipótese entendiam que os raios catódicos eram ondas eletromagnéticas, sujeitas a ação de campos magnéticos, uma forma de "luz magnética"6 (JAUNCEY apud MARTINS, 2012a).

Perrin realizou um experimento no qual, além de desviar os raios submetidos a ação de um campo magnético, ainda os direcionava para dentro de um cilindro metálico colocado no interior do tubo de descargas. Este cilindro era ligado a um eletroscópio de lâminas que indicava a presença de cargas negativas no cilindro metálico, sempre que os raios eram desviados para o interior do mesmo (PERRIN, 1895), evidenciando, dessa forma, a presença de cargas negativas nos raios catódicos. Essa contribuição de Perrin ofereceu argumentos favoráveis à hipótese dos raios catódicos como partículas, contribuindo para os experimentos realizados por J. J. Thomson, como veremos oportunamente.

A fundamentação teórica adequada ao contexto do período e os experimentos realizados para defender ambas as hipóteses são exemplos que mostram como os cientistas da época divergiam em relação às teorias e hipóteses que tentavam explicar o fenômeno dos raios catódicos, evidenciando o processo coletivo e não linear da construção do conhecimento científico. Conforme Hidalgo et al. (2018) observam em recente pesquisa, em geral, os pensadores somente são citados nos livros didáticos pelas contribuições "que deram certo" mediante o que é aceito pela ciência atual, e todo esse rico processo de desacordo é omitido, como se não tivesse sido relevante para a construção da ciência. Essas distorções, ainda presentes no ambiente escolar, fomentam uma visão ingênua de que a ciência é uma sequência

\footnotetext{
5 Uma motivação para Lenard não se dedicar à investigação de todos os fenômenos observados durante suas experiências com raios catódicos pode ser vista em Martins (2012a, p. 24, nota 16).

6 Para a concepção sobre a natureza da luz na época, sua deflexão magnética não parecia ser impossível.
} 
de descobertas geniais, realizada por personagens que nunca se enganam, nunca cometem erros e apartada da dimensão humana (D’AMBRÓSIO, 2004; MARTINS, 2006) ${ }^{7}$.

O Quadro 5 traz representações de aparatos experimentais da época.

Quadro 5: Representações de aparatos experimentais utilizados na investigação sobre raios catódicos em publicações da segunda metade do século XIX e início do século XX.

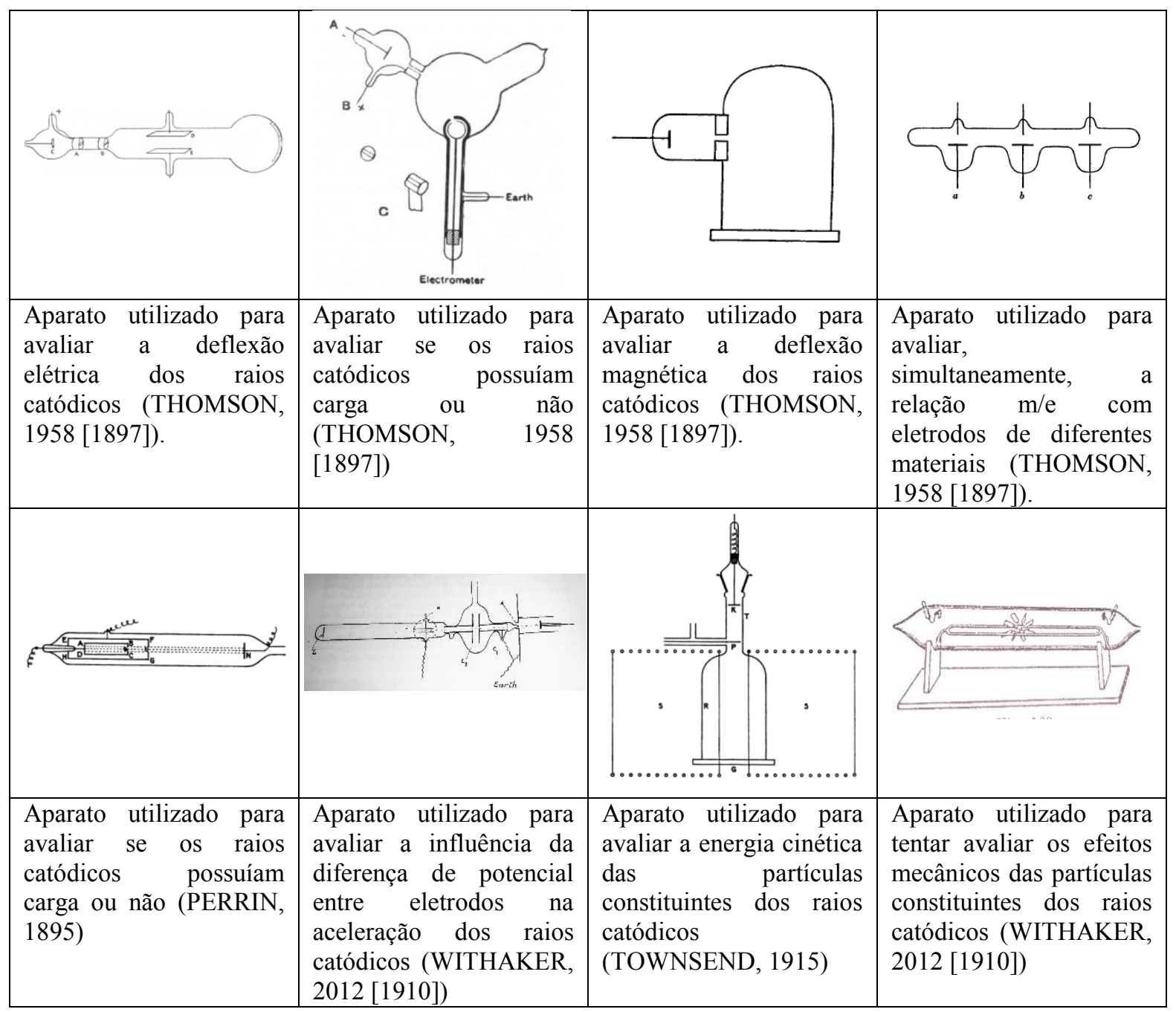

Fonte: autores.

Nos dias atuais, como já dissemos, Thomson é comumente apresentado como o descobridor do elétron (BUCHWALD; WARWICK, 2001), ou de uma forma menos ingênua,

\footnotetext{
7 Apesar de Thomson ser comumente citado como um defensor da teoria corpuscular dos raios catódicos, em janeiro de 1896, apenas 1 ano antes da publicação de Cathode Rays ele apresentou um trabalho à Cambridge Philosofical Society, onde sugeria uma explicação para os raios x (outro fenômeno intensamente estudado na época) em função de perturbações do éter (THOMSON apud MARTINS, 2012a).
} 
como aquele que conseguiu mensurar a velocidade $(v)$ e a relação carga/massa ${ }^{8}(e / m)$ das partículas constituintes dos raios catódicos e identificá-las como sendo a menor porção de matéria conhecida até então. Mas, será que estas são realizações que realmente deveriam ser atribuídas somente a ele?

Além de todos os antecedentes já mencionados, o próprio Thomson (2012 [1903]) cita dois outros cientistas que teriam determinado valores para a velocidade $v$ e a relação $e / m$ com a mesma ordem de magnitude de seus experimentos, antes mesmo deste ter realizado suas aferições, são eles: Johann Emil Wiechert (1861-1928) e Walter Kaufmann (1871-1947).

Em janeiro de 1897, Wiechert, um físico e sismologista alemão, combinando a deflexão magnética com a energia cinética das partículas

\begin{abstract}
foi o primeiro a mostrar que a velocidade dos raios catódicos em alguns casos era em torno de um décimo da velocidade da luz, e que a relação e/m para as partículas dos raios catódicos estava entre 4000 e 2000 vezes maior que o valor de $\mathbf{E} / \mathbf{M}$ correspondente para um átomo de hidrogênio em eletrólise. Ele atribuiu esse grande valor de e/m a infima massa $\boldsymbol{m}$ e considerou que as cargas $\boldsymbol{e}$ e $\boldsymbol{E}$ eram as mesmas (TOWNSEND, 1915, p. 461).
\end{abstract}

Utilizando os mesmos princípios de Wiechert, em julho de 1897, seu compatriota Kaufmann chegou a resultados semelhantes aos de Thomson sobre a magnitude da relação $e / m$ dos raios catódicos (TOWNSEND, 1915). Porém, como explica Weinberg (2003, p. 65, grifos nossos),

[...] enquanto Thomson estava medindo a relação massa/carga, uma experiência semelhante era realizada em Berlim por Walter Kaufmann, com resultados que nós sabemos agora serem, realmente, mais precisos que os de Thomson. Mas Kaufmann não reivindicou ter descoberto uma partícula fundamental. Como Hertz e outros fisicos na Alemanha e na Austria, Kaufmann era fortemente influenciado pela filosofia científica do físico e filósofo vienense Ernst Mach (18361916) e seu círculo, que considerava que não era cientifico preocupar-se com entidades hipotéticas, como átomos que não poderiam ser diretamente observados.

A ciência alemã do final do século XIX era fortemente influenciada pelo positivismo, que colocava os dados experimentais, não metafísicos, como único fundamento (BRAGA; GUERRA; REIS, 2012). Em tal cenário a admissão de entes inobserváveis experimentalmente era bastante criticada (MARTINS, 2012b). Esse contexto pode ter sido um dos motivos para explicar o porquê de os trabalhos de Wiechert e Kaufmann não terem tido significativo reconhecimento, conforme discutiremos.

\footnotetext{
${ }^{8}$ Como na época não havia uma forma direta de se mensurar, nem a quantidade de partículas (átomos, íons ou corpúsculos) envolvidas nos experimentos, nem a massa dessas partículas, os cientistas aplicavam um método indireto para avaliar estas características, como exemplo, a relação carga/massa (e/m) (CHALMERS, 1949).
} 
Thomson (2012 [1903]) ainda cita uma outra importante contribuição. Os experimentos realizados por Sir Franz Arthur Friedrich Schuster (1851-1934), que em 1890 calculou a relação carga/massa das partículas constituintes dos raios catódicos, utilizando-se da medida do raio da trajetória imposta por uma deflexão magnética sobre os mesmos. ${ }^{9}$ Conforme Thomson (2012 [1903]) aponta, Schuster foi o primeiro a utilizar o método de determinação da velocidade e da relação carga/massa dos raios catódicos a partir da sua deflexão magnética e da diferença de potencial entre os eletrodos de descarga (cátodo e ânodo).

Schuster tinha uma explicação diferente para a composição dos raios catódicos. Assim como alguns outros pesquisadores da época, ele supunha que estes eram constituídos por íons resultantes da dissociação do gás residual no interior dos tubos, causada pela força eletrostática que existia entre o cátodo e o ânodo (WHITTAKER, 2012 [1910]). Seus cálculos indicavam uma ordem de magnitude entre $10^{3}$ e $10^{5}$ para a relação carga/massa das partículas, um valor um tanto distante dos encontrados posteriormente. Mas, eram condizentes com pressupostos teóricos que adotou e com os recursos técnicos que ele próprio desenvolveu em seus experimentos, que foram realizados sete anos antes de Wiechert, Kaufmann e Thomson. Smith (2001) considera que Shuster propôs inovações nas técnicas de medição da relação carga/massa das partículas constituintes dos raios catódicos.

Em maio de 1897 (The Electrician), e depois em outubro deste mesmo ano (Philosophical Magazine), J. J. Thomson publica seu mais conhecido artigo, Cathode Rays, justificando que os experimentos ali descritos tinham como objetivo a esperança de obter alguma informação sobre a natureza dos raios catódicos (THOMSON, 1958 [1897]).

Em Cathode rays, J. J. Thomson removeu uma importante objeção que havia sido imposta por Hertz sobre a teoria corpuscular dos raios catódicos: o fato de que estes não eram deflexionados por um campo eletrostático de baixa intensidade. Thomson atingiu esse objetivo demonstrando que, em tubos com um melhor grau de exaustão, os raios catódicos podiam ser deflexionados por campos eletrostáticos criados por uma diferença de potencial tão baixa quanto dois volts (THOMSON, 1958 [1897]). O problema nos experimentos de Hertz era que o gás residual no interior dos tubos era ionizado pelos raios catódicos, os íons originados se depositavam sobre as placas metálicas responsáveis por criarem o campo elétrico de deflexão, anulando-o (WHITTAKER, 2012 [1910]). O objetivo de Thomson só pôde ser alcançado devido a uma melhoria na técnica de construção das bombas de vácuo, responsáveis pela exaustão do gás do interior dos tubos (CHALMERS, 1949).

Essa dependência da tecnologia nos experimentos traz mais alguns elementos contextuais para pensarmos aspectos das práticas científicas no desenvolvimento da ciência, além das concepções teóricas prévias, que dirigem o olhar para os resultados, a questão dos entes inobserváveis e da colaboração entre cientistas.

\footnotetext{
9 Este é o método utilizado por alguns dos kits comerciais e/m apparatus atuais. Para uma comparação entre o experimento histórico, os kits comerciais e uma proposta de baixo custo consulte Neves et al., 2019.
} 
Sobre esse evento, Falconer (2001) e Achinstein (2001) sugerem que a deflexão eletrostática dos raios catódicos parece ter sido um aspecto que Thomson formalizou antes de qualquer outro pesquisador, que tenham estudado o tema. As deflexões magnética e eletrostática dos raios catódicos permitiram a Thomson calcular a velocidade dos mesmos, encontrando uma ordem de magnitude de $10^{9}$ centímetros por segundo, e demonstrar que a relação $m / e$ dos constituintes desses raios possuía uma ordem de magnitude de $10^{-7}$, apenas a milésima parte da relação $\mathrm{m} / \mathrm{e}$ do átomo de hidrogênio em eletrólise, a menor conhecida até então (THOMSON, 1958 [1897]) ${ }^{10}$.

As medidas da relação carga/massa foram realizadas de duas formas complementares por Thomson. Uma, utilizando o cálculo da velocidade e a medição das deflexões magnéticas e eletrostática dos raios e, outra, medindo a diferença de temperatura que o impacto desses raios causava em uma placa metálica. Além disso, Thomson realizou testes com cátodos de diferentes materiais e com diferentes gases no interior do tubo, obtendo sempre resultados semelhantes, levando-o a acreditar que os corpúsculos constituintes dos raios catódicos eram sempre os mesmos, independentemente do material utilizado ${ }^{11}$.

O quadro 6 sintetiza algumas contribuições para a compreensão dos raios catódicos.

Quadro 6: Algumas contribuições para a compreensão da natureza dos raios catódicos.

\begin{tabular}{|c|c|c|c|}
\hline $\begin{array}{l}\text { Franz Arthur Friedrich } \\
\text { Schuster. }\end{array}$ & $\begin{array}{ll}\text { Johann } & \text { Emil } \\
\text { Wiechert. } & \end{array}$ & Joseph John Thomson. & Walter Kaufmann. \\
\hline $\begin{array}{l}\text { Método: } \\
\text { deflexão magnética } \\
\text { dos raios catódicos e } \\
\text { diferença de potencial } \\
\text { entre cátodo e ânodo. }\end{array}$ & $\begin{array}{l}\text { Método: } \\
\text { deflexão magnética } \\
\text { dos raios catódicos. }\end{array}$ & $\begin{array}{l}\text { Método: } \\
\text { deflexão elétrica e } \\
\text { magnética dos raios } \\
\text { catódicos; }{ }^{*} \text { e } \\
\text { deflexão magnética } \\
\text { dos raios catódicos e } \\
\text { efeito de } \\
\text { aquecimento }{ }^{* *} \text {. }\end{array}$ & $\begin{array}{l}\text { Método: } \\
\text { deflexão magnética } \\
\text { dos raios catódicos e } \\
\text { diferença de potencial } \\
\text { entre cátodo e ânodo. }\end{array}$ \\
\hline $\begin{array}{l}\text { Relação } e / m: \\
1.10^{5}>\mathrm{e} / \mathrm{m}>1.10^{3} \text {. }\end{array}$ & $\begin{array}{l}\text { Relação } e / m: \\
4.10^{7}>\mathrm{e} / \mathrm{m}>4.10^{6} .\end{array}$ & $\begin{array}{l}\text { Relação e/m: } 7,7 \cdot 10^{6^{*}} \\
\text { e } 1,17.10^{7 * *}\end{array}$ & $\begin{array}{l}\text { Relação e/m: } \\
1,86.10^{7} .\end{array}$ \\
\hline $\begin{array}{l}\text { Publicação: } \\
1890 .\end{array}$ & $\begin{array}{l}\text { Publicação: } \\
\text { janeiro de } 1897 .\end{array}$ & $\begin{array}{l}\text { Publicação: } \\
\text { maio e outubro de } \\
1897 .\end{array}$ & $\begin{array}{l}\text { Publicação: } \\
\text { julho de } 1897 .\end{array}$ \\
\hline
\end{tabular}

Fonte: autores. 10 As demonstrações matemáticas de como Thomson inferiu a velocidade e a relação e/m das partículas podem
ser consultadas em Neves e colaboradores (2019).

${ }^{11}$ Smith (2001) cita que estas foram contribuições demonstradas previamente por Thomson. 
Levando em conta apenas as datas de publicações dessas pesquisas, sintetizadas no Quadro 6 acima, podemos supor que Thomson não teria sido o primeiro a determinar as ordens de grandezas da velocidade e da relação carga/massa das partículas constituintes dos raios catódicos. Contudo, poderíamos ainda supor, que as pesquisas de Wiechert, Thomson e Kaufmann ocorreram em momentos cronologicamente diferentes de suas publicações, assim, não se pode afirmar quem primeiro chegou a estes resultados. Nesse sentido, a afirmação de Achinstein (2001) de que "os fatos históricos sobre quem sabia o quê e quando são muito complexos", mostra-se muito coerente.

Mas, se não podemos afirmar com exatidão quem "descobriu"12 o elétron, ou a ordem de magnitude da velocidade ou da relação da carga/massa das partículas constituintes dos raios catódicos, por que Thomson herdou a fama por tê-lo feito?

Além de argumentos epistêmicos, outros fatores contextuais também influenciam na aceitação, disseminação de ideias e crédito sobre realizações nas ciências, assim como o apagamento de colaboradores ou ajudantes nos laboratórios. Pesquisas históricas recentes sobre o desenvolvimento das hipóteses da constituição desses raios sinalizam que um dos motivos para Thomson ter recebido mais crédito que Kaufmann e Wiechert era o fato do quanto a comunidade científica (alemã, inglesa e francesa) que apoiava cada pesquisador, considerava importante aquela descoberta (ACHINSTEIN, 2001). Como citado anteriormente, a comunidade científica alemã da época, na qual estavam inseridos Kaufmann e Wiechert, não considerava científico preocupar-se com entidades hipotéticas que não podiam ser observadas.

Falconer (2001, p. 92) atribui a glória de Thomson ao "grupo grande e cada vez mais poderoso dos seus ex-alunos de pesquisa que enalteciam o seu trabalho". Faziam parte desse grupo, Max Born (1882-1970), Charles Thomson Rees Wilson (1869-1959), Sir John Sealy Edward Townsend (1868-1957) e Ernest Rutherford (1871-1937) ${ }^{13}$.

Kragh (2001, p. 203) concluiu na sua investigação sobre o episódio que,

Com os experimentos de Thomson sobre raios catódicos de 1897 o elétron se tornou uma realidade material, uma particula elementar, e a base de uma teoria da matéria. Este foi um importante elemento na descoberta do elétron, e um que distinguiu a descoberta de Thomson das medidas da relação massa/carga (m/e) realizadas na Alemanha por Emil Wiechert e Walter Kaufmann.

Já Smith (2001), sugere que um dos motivos para Thomson ter se sobressaído historicamente sobre seus contemporâneos pesquisadores, não foram os resultados obtidos em 1897 e sim aqueles advindos das pesquisas e experimentos de 1898 e 1899, quando Thomson

\footnotetext{
12 Ao discutir sobre quem realmente descobriu o elétron, Achinstein (2001) expõe algumas considerações filosóficas e tenta estabelecer um razoável conceito de descoberta.

13 O prestígio de Thomson influenciou também a aceitação de seu modelo atômico, em um contexto de modelos concorrentes, os quais eram bem fundamentados e mais promissores, quanto ao que a comunidade científica acabaria por adotar. Veja uma análise em Vasconcelos e Forato (2018).
} 
obteve respostas para questões sobre qual papel o elétron desempenhava no fenômeno elétrico.

Atualmente, apesar de Thomson ser o mais lembrado e conhecido entre todos os indivíduos que um dia estudaram a natureza dos raios catódicos, em um interessante estudo, Gooday (2001) propõe que esse processo de reconhecimento foi demorado e complexo e que os debates a respeito da apropriação dos resultados de Thomson sobre os corpúsculos davamse em distintas frentes de pesquisa, como a espectroscopia, os raios catódicos, os raios x e a radioatividade, entre outros. Somente por volta de 1900, passou-se a atribuir uma grande importância a seus trabalhos e seus resultados foram então amplamente assimilados ${ }^{14}$.

Voltando as atenções novamente ao experimento, podemos perceber que muitos livros didáticos e de divulgação científica apresentam a imagem do assim chamado, clássico "experimento de Thomson" do tubo de descargas elétricas (Fig. 1). Uma representação simplista, que fomenta uma imagem distorcida do desenvolvimento científico, como se, com um único experimento, o pesquisador pudesse fundamentar todas as peculiaridades de uma complexa teoria (Gil-PÉREZ et al., 2001; MARTINS, 2006).

Tais narrativas históricas ignoram completamente que Thomson realizou ao menos cinco diferentes montagens experimentais, com tubos de formas variadas, cátodos e ânodos de diferentes materiais, ora utilizando somente a deflexão magnética, ora somando a esta a deflexão eletrostática, e, em outro momento, medindo a variação de temperatura e o tempo necessário para essa variação (THOMSON, 2012 [1897]).

Além disso, raramente mencionam as contribuições de Hertz, Perrin, Lenard, Röntgen, Hermann von Helmholtz (1821-1894) e Kristian Olaf Bernhard Birkeland (18671917) entre outros, todos citados por Thomson 2012 ([1897]), em um claro exemplo de como a ciência é desenvolvida não por indivíduos isolados, mas sim coletivamente, ou por colaboração entre grupos ou entre pesquisadores, em muitos casos. Deixam de relatar que ele repetiu por muitas vezes um mesmo experimento até que pudesse obter resultados razoavelmente coerentes, evidenciando a não existência de um método único, algorítmico e infalível no empreendimento científico.

Ainda, deixam de explorar o potencial que o episódio possui para favorecer a compreensão de alguns conceitos físicos que são apresentados por Thomson (2012 [1897]) no seu célebre artigo, como, por exemplo, a ação da força magnética e elétrica sobre uma partícula carregada em repouso ou em movimento, ou a formação de um campo magnético uniforme entre duas bobinas colocadas paralelamente.

É difícil, ou mesmo impossível, estabelecer um início para o desenvolvimento de um conceito ou uma teoria, mas podemos considerar que os estudos sobre raios catódicos se

\footnotetext{
14 É importante ressaltar que não pretendemos transmitir uma ideia de que Thomson havia chegado a conclusões definitivas sobre a natureza da eletricidade e da matéria, apenas que suas propostas eram o que melhor se poderia oferecer sobre o assunto segundo os pesquisadores da época. Kragh (2001) cita como exemplo de um equívoco posteriormente refutado o fato de que Thomson considerava que a massa do átomo era resultado da soma das massas dos corpúsculos (elétrons) que o constituíam.
} 
desenvolveram a partir das pesquisas com descargas elétricas em tubos contendo gases rarefeitos, algumas décadas antes de Thomson e antes de alguns de seus contemporâneos realizarem os seus próprios experimentos.

Apoiando a asserção do parágrafo anterior, tanto historiadores da primeira metade do século XX (TOWNSEND, 1915; WHITTAKER, 2012 [1910]; CHALMERS, 1949) quanto da atualidade (ACHINSTEIN, 2001; WEINBERG, 2003; MAIA, SERRA; PERES, 2010; MARTINS, 2012a) apontam alguns dos pensadores que se dedicaram ao estudo desse fenômeno. No Quadro 7 são apresentados alguns desses pensadores.

Quadro 7: Alguns dos pensadores que se dedicaram ao estudo dos raios catódicos e algumas de suas contribuições.

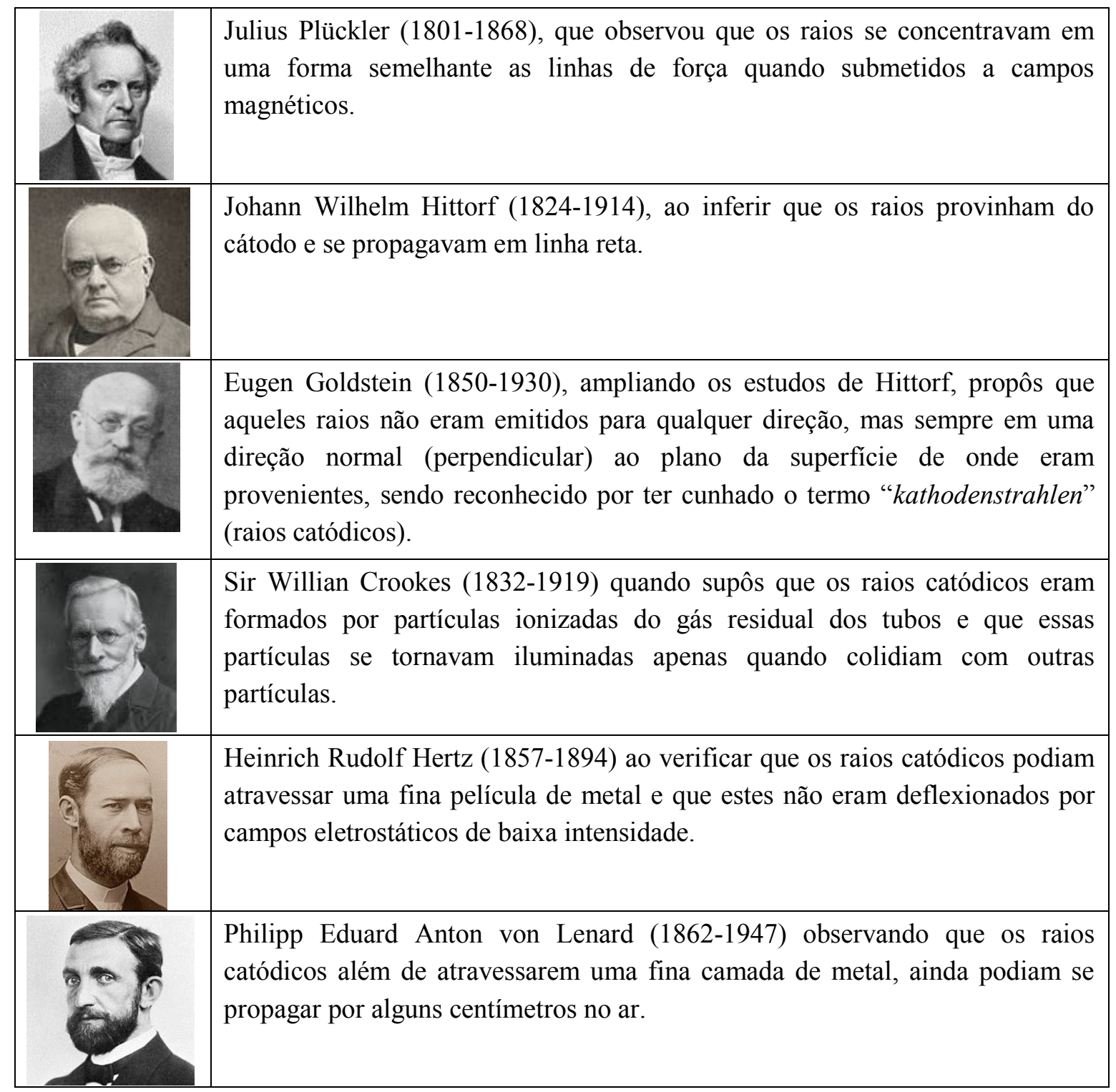




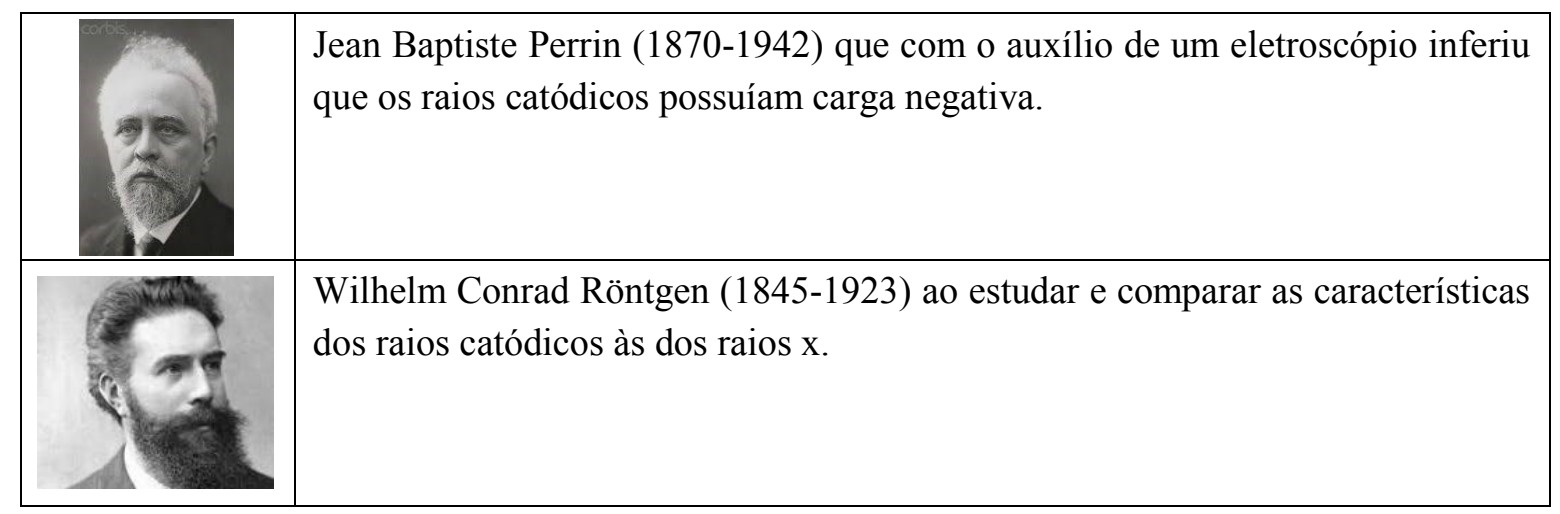

Fonte: autores.

Essas são algumas das contribuições mais conhecidas, a partir de 1850, para o desenvolvimento das ideias que levaram a proposição de um constituinte universal, o elétron.

Obviamente, estas contribuições não ocorreram de forma linear, não necessariamente de forma cumulativa e algumas foram, inclusive, contestadas por observações posteriores. Nem sempre as interpretações sobre o fenômeno observado convergiam para um ponto comum, como vimos. No entanto, os inúmeros experimentos, interpretações, conclusões, hipóteses refutadas e mesmo divergências de ideias contribuíram para o desenvolvimento das bases conceituais aceitas pela comunidade científica, que foram fundamentais para o trabalho de Thomson. Nessa complexidade de interações, além de outros aspectos contextuais que também concorrem para o desenvolvimento de uma teoria, fica evidenciado o processo coletivo da construção do conhecimento, em oposição às descobertas ocasionais ou pela súbita inferência genial (MARTINS, 2006).

Um aspecto fundamental para as conclusões de Thomson foi o desenvolvimento e a evolução de aparatos tecnológicos que ele utilizou. "Há momentos na história em que uma nova tecnologia abre grandes possibilidades para a ciência pura" (WEINBERG, 2015, p. 231), como o caso para os estudos sobre descargas elétricas através de gases rarefeitos.

Whittaker (2012 [1910]) e Weinberg (2003), também em épocas distintas, indicam que a evolução daquelas pesquisas não poderia acontecer sem o desenvolvimento de técnicas, aparatos e instrumentos que aprimoraram os laboratórios da época. Veja, no quadro 8, outros pensadores que se dedicaram ao estudo dos raios catódicos e algumas de suas contribuições experimentais importantes para o referido estudo.

Para entender a importância dessas soluções experimentais no estudo dos raios catódicos, Weinberg (2003, p. 18) considera que "o ponto de virada veio com a invenção de uma bomba de ar realmente efetiva" e Martins (2012a, p. 21) afirma que "o estudo daquilo que chamamos de "raios catódicos" está vinculado ao aperfeiçoamento de bombas de vácuo, em meados do século XIX', ambos se referindo aos trabalhos de Heinrich Geissler. A respeito do desenvolvimento dessas pesquisas, sobre descargas elétricas em gases rarefeitos, é interessante destacar uma consideração de Whittaker (2012 [1910], p. 390): 
Quadro 8: Pensadores que se dedicaram ao estudo dos raios catódicos e suas contribuições experimentais.

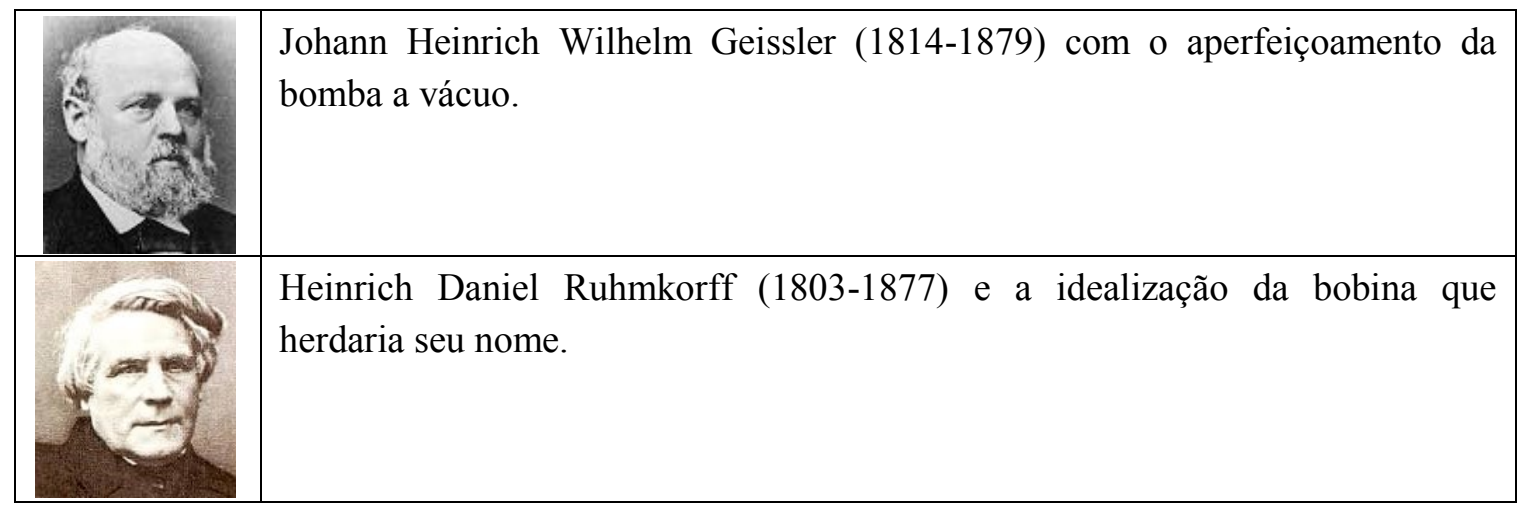

Fonte: autores.

[...] apesar de muitas gerações de filósofos terem estudado os efeitos notáveis que são apresentados pela passagem de uma corrente através de um gás rarefeito, até recentemente [1910], não havia sido descoberta uma teoria satisfatória para o fenômeno.

Podemos pensar, a partir deste breve estudo, que o estabelecimento da teoria sobre a natureza dos raios catódicos tenha sido fruto de um esforço coletivo de muitos estudiosos e o próprio artigo de Thomson, Cathode Rays, fornece importantes pistas nesse sentido.

Ficam algumas questões para reflexão, sobre o papel que o contexto em que cada pensador estava inserido, poderia ter tido sobre a ciência. Além das variáveis já mencionadas, nessa perspectiva para o recorte histórico, que afetaram a construção dos conceitos em si, quanto de aspectos sociais, políticos ou econômicos poderiam ter interferido nos investimentos e no desenvolvimento técnico para possibilitar e favorecer esses estudos? Quanto a aspectos filosóficos ou metafísicos, que concepções pessoais podem ter influenciado as pesquisas? Teriam as concepções positivistas específicas aos diferentes contextos europeus, em que esses pensadores estavam imersos, interferido, de algum modo, no desenvolvimento da ciência?

Outro conteúdo importante para reflexão, volta-se para os apagamentos em fontes primárias, secundárias e em periódicos especializados que não mencionam a contribuição de pesquisadores de outras nacionalidades, de outras etnias e de mulheres para o estudo dos raios catódicos, tampouco apresentam os sujeitos invisíveis que trabalhavam nos laboratórios. Essas omissões são fundamentais de serem discutidas, pois certamente muito nos ensinam sobre diferentes fatores culturais que influenciam nas ciências, no seu desenvolvimento e em sua historiografia (LIMA, 2019).

Além das questões, elencadas anteriormente, docentes ainda podem propor outras. Mesmo com tantos pesquisadores envolvidos no tema, por que os livros atuais ainda mantêm a versão ultrapassada, ingênua e estereotipada sobre o episódio? Seria apenas por desconhecimento? Como esses desacordos entre os cientistas, sobre hipóteses e resultados 
observacionais, podem ser considerados elementos da prática científica que fortalecem o desenvolvimento das ciências?

\section{Considerações finais}

O principal objetivo deste trabalho é oferecer, como resultado de uma pesquisa orientada por uma concepção historiográfica atual das ciências, um material que problematize alguns aspectos da NDC e explicite aspectos do desenvolvimento científico, tendo em primeiro plano aqueles relacionados aos experimentos sobre a constituição dos raios catódicos ao final do século XIX. Sentimos essa necessidade a partir do entendimento de que o livro didático e os materiais de divulgação científica ainda são as principais fontes de concepções equivocadas sobre a História da Ciência. Mesmo em aulas com abordagem experimental para o tema, a narrativa histórica que permeia os discursos orais ou escritos pauta-se em livros didáticos "clássicos" para o ensino superior ou médio. Os recortes abaixo, todos extraídos de livros geralmente utilizados em cursos de bacharelado e licenciatura em Física, ilustram exemplos dessa nossa afirmação.

$$
\begin{aligned}
& \text { [...] o físico J.J. Thomson, trabalhando nos laboratórios Cavendish em } \\
& \text { Cambridge ... estudava a matéria radiante de Crookes. Ele concordava que os raios } \\
& \text { eram formados por um feixe de partículas, mas seus experimentos indicavam que } \\
& \text { estas eram bem menores que o átomo [...] Thomson havia descoberto indícios da } \\
& \text { existência de uma partícula subatômica, o elétron (MOSLEY; LINCH, 2011, p. 91). } \\
& \text { Oexperimento de Thomson pode ser considerado um marco na história da ciência, } \\
& \text { pois ele conseguiu medir elm para uma partícula subatômica usando apenas um } \\
& \text { multímetro, um amperímetro e uma régua (TIPLER; LLEWELLYN, 2014, p. 76). }
\end{aligned}
$$

Todos esses exemplos sugerem que Thomson teria sido o único a realizar experimentos com raios catódicos (ou ao menos, o único que obteve sucesso), a despeito do próprio cientista indicar o contrário, justamente em seu artigo de publicação de seus experimentos.

Obviamente, esse é apenas um dentre os muitos outros episódios científicos narrados de forma semelhantemente inadequada nos livros didáticos ou de divulgação científica, sendo impraticável ao professor discutir todos com a devida profundidade. No entanto, cremos que abordagens como a defendida neste artigo contribuem para promover, quando utilizadas de forma reflexiva, uma mudança no olhar dos professores em serviço, em formação inicial ou continuada quando se depararem com textos com características semelhantes.

Uma proposta didática para acompanhar essa abordagem histórica foi apresentada em Neves e colaboradores (2019), com explicações detalhadas para uma montagem experimental, um caminho adequado para a tomada de medidas e realização de cálculos pertinentes, bem como sugestões de discussões e encaminhamentos. 
Há, também, a possibilidade de que formadores de professores utilizem apenas a reprodução experimental (Neves et al., 2019) ou o relato histórico apresentado neste artigo. Nesse caso, como o texto histórico conta com aproximadamente 5400 palavras, torna-se possível para utilização em uma ou duas aulas, compondo uma atividade, ou que a partir dele, os professores proponham atividades para alunos da educação básica, por exemplo.

\section{Referências bibliográficas}

ACHINSTEIN, P. Who really discovered the electron. In: BUCHWALD, J. Z.; WARWICK, A. (Ed.). Histories of the electron: the birth of microphysics. London: MIT Press, 2001. $514 \mathrm{p}$.

ALLCHIN, D. Pseudohistory and Pseudoscience. Science \& Education, v. 13, n. 3, p. 179$195,2004$.

BRAGA, M.; GUERRA, A.; REIS, J. C. A Física experimental numa perspectiva históricofilosófica. In: PEDUZZI, L. O. Q.; MARTINS, A. F. P.; FERREIRA, J. M. H. (Orgs.). Temas de História e Filosofia da Ciência no Ensino. Natal: EDUFRN, 2012. 372 p.

BUCHWALD, J. Z.; WARWICK, A. Introduction - Corpuscles and Electrons. In: BUCHWALD, J. Z.; WARWICK, A. (Ed.). Histories of the electron: the birth of microphysics. London: MIT Press, 2001. 514 p.

CHALMERS, T. W. Historic researches - Chapters in the History of Physical and Chemical Discovery. London: Morgan Brothers Ltda, 1949. 288 p.

D’AMBROSIO, U. Tendências historiográficas na história da ciência. In: ALFONSOGOLDFARB, A. M.; BELTRAN, M. H. R. (Orgs.). Escrevendo a História da Ciência: tendências, propostas e discussões historiográficas. São Paulo: EDUC; Livraria da Física 2004. 229 p.

D’AMBRosiO, U. Uma história concisa da matemática no Brasil. 2. ed. Petrópolis: Vozes, 2011. 126 p.

DEBUS, A. G. Ciência e história: o nascimento de uma nova área. In: ALFONSOGOLDFARB, A. M.; BELTRAN, M. H. R. (Orgs.). Escrevendo a História da Ciência: tendências, propostas e discussões historiográficas. São Paulo: EDUC; Livraria da Física 2004. 229 p. 
FALCONER, I. Corpuscles to eletrons. In: BUCHWALD, J. Z.; WARWICK, A. (Ed.). Histories of the electron: the birth of microphysics. London: MIT Press, 2001. 514 p.

FORATO, T. C. M. A natureza da ciência como saber escolar: um estudo de caso a partir da história da luz. 2009. Tese (Doutorado) - São Paulo, Faculdade de Educação, USP.

FORATO, T. C. M. Preparação de professores para problematização da pseudo-história em materiais didáticos. Enseñanza de las Ciencias, v. extra, p. 1316-1321, 2013.

FORATO, T. C. M.; MARTINS, R. A.; PIETROCOLA, M. Enfrentando obstáculos na transposição didática da História da Ciência para a sala de aula. In: PEDUZZI, L. O. Q.; MARTINS, A. F. P.; FERREIRA, J. M. H. (Orgs.). Temas de História e Filosofia da Ciência no Ensino. Natal: EDUFRN, 2012. 372 p.

FORATO, T. C. M.; MARTINS, R. A.; PIETROCOLA, M. Historiografia e Natureza da Ciência na sala de aula. Caderno Brasileiro de Ensino de Física, v. 28, n. 1, p. 27-59, abr. 2011.

FORATO, T. C. M.; BAGDONAS, A.; TESTONI, L. Episódios históricos e Natureza da Ciência na formação de professores. Enseñanza de las ciencias - Digital, v. extra, p. 35113516, 2017.

GIL-PÉREZ, D. et. al. Para uma imagem não deformada do trabalho científico. Ciência \& Educação, v. 7, n. 2, p. 125-153, 2001.

GOODAY, G. The questionable matter of electricity. In BUCHWALD, J. Z.; WARWICK, A. (ed.). Histories of the electron: the birth of microphysics. London: MIT Press, 2001. 514 p.

HEERING, P. The stabilization of experimental procedures: Historical and educational aspects. Revista Brasileira de História da Ciência, v. 7, n. 2, p. 142-148, dez. 2014.

HIDAlgO, J. M. et. al. A História da Ciência (Distorcida ou Ausente) em Livros Didáticos: O Conteúdo sobre o "Experimento de Torricelli" como Estudo de Caso. Alexandria, v. 11, n. 1, p. 101-124, maio 2018.

JARDIM, W.; GUERRA, A. República das Letras, Academias e Sociedades Científicas no século XVIII: a garrafa de Leiden e a ciência no ensino. Caderno Brasileiro de Ensino de Física, v. 34, n. 3, p. 774-797, dez. 2017.

KRAGH, H. The protyle materialized. In: BUCHWALD, J. Z.; WARWICK, A. (Ed.). 
Histories of the electron: the birth of microphysics. London: MIT Press, 2001. 514 p.

KUHN, T. S. A estrutura das revoluções científicas. 12. ed. São Paulo: Perspectiva, 2013 [1962]. 323 p.

LIMA, I. P. C. Lise Meitner e a Fissão Nuclear: Caminhos para uma narrativa feminista. 2019. Tese (Doutorado em Ensino, Filosofia e História das Ciências) - Programa de Pósgraduação em Ensino, Filosofia e História das Ciências, Universidade Federal da Bahia.

LOPES, C. V. M.; MARTINS, R. A. J. J. Thomson e o uso de analogias para explicar os modelos atômicos: o 'pudim de passas' nos livros texto. In: ENCONTRO NACIONAL DE PESQUISA EM EDUCAÇÃO EM CIÊNCIAS, VII, 2009, Florianópolis.

MAIA, E.; SERRA, I.; PERES, M. The gas discharges in history and teaching of physics and chemistry. Travaux de Laboratoire. Tome L, v. II, 2010.

MARTINS, A. F. P. História e filosofia da ciência no ensino: há muitas pedras nesse caminho. Caderno Brasileiro de Ensino de Física, v. 24, n. 1, p. 112-131, abr. 2007.

MARTINS, L. A. C. P. História da Ciência - objetos, métodos e problemas. Ciência \& Educação, v. 11, n. 2, 2005.

MARTINS, R. A. Como não escrever sobre história da física - um manifesto historiográfico. Revista Brasileira de Ensino de Física, v. 23, n. 1, p. 113-129, mar. 2001.

MARTINS, R. A. Ciências versus historiografia: os diferentes níveis discursivos nas obras sobre história da ciência. In: ALFONSO-GOLDFARB, A. M.; BELTRAN, M. H. R. (orgs.). Escrevendo a História da Ciência: tendências, propostas e discussões historiográficas. São Paulo: EDUC; Livraria da Física 2004. 229 p.

MARTINS, R. A. Introdução: A História das Ciências e seus usos na educação. In: SILVA, Cibelle Celestino (ed.). Estudos de história e filosofia das ciências: subsídios para aplicação no ensino. São Paulo: Livraria da Física, 2006. 381 p.

MARTINS, R. A. A física no final do século XIX: modelos em crise. Apresentação em Slides. Disponível em: <http://pt.slideshare.net/ronaldotesla/fsica-no-sculo-xix-presentation>. Acesso em: 03 abr. 2021. Publicado em 17 de novembro de 2008. 
MARTINS, R. A. Seria possível uma história da ciência totalmente neutra, sem qualquer aspecto whig? Boletim de História e Filosofia da Biologia, v. 4, n. 3, p. 4-7, set. 2010.

MARTINS, R. A. Becquerel e a descoberta da radioatividade: uma análise crítica. Campina Grande: EDUEPB; São Paulo: Livraria da Física, 2012a. 475 p.

MARTINS, R. A. O éter e a óptica dos corpos em movimento: a teoria de Fresnel e as tentativas de detecção do movimento da Terra, antes dos experimentos de Michelson e Morley (1818-1880). Caderno Brasileiro de Ensino de Física, v. 29, n. 1, p. 52-80, abr. 2012b.

MEDEIROS, A.; MONTEIRO JR, F. N. Algumas tendências na utilização de reconstruções experimentais históricas no ensino de física. In: SEMINÁRIO DE HISTÓRIA DA CIÊNCIA, 8, 2001, Rio de Janeiro. Anais... Rio de Janeiro: [s.n.], 2001. Disponível em: $<$ http://alexandremedeirosfisicaastronomia.blogspot.com.br/2011/11/algumas-tendencias-nautilizacao-de.html>. Acesso em: 03 abr. 2021.

MOSLEY, M.; LYNCH, J. Uma história da ciência. Rio de Janeiro: Jorge Zahar Editor Ltda, 2011. 288 p.

MOURA, B. A.; FORATO, T. C. M. (Orgs.). Histórias das ciências, epistemologia, gênero e arte: ensaios para a formação de professores. São Bernardo do Campo: Editora UFABC, 2017. $280 \mathrm{p}$.

NEVES, D. R. M. et al. Uma proposta de baixo custo para experimentos com raios catódicos. Caderno Brasileiro de Ensino de Física, v. 36, n. 1, p. 256-286, abr. 2019.

OLIVEIRA, W. C.; DRUMMOND, J. M. H. F. Refletindo sobre desafios à inserção didática da História e Filosofia da Ciência em oficina de formação docente. Alexandria, v. 8, n. 3, p. 151-179, nov. 2015.

PERRIN, J. B. New experiments on the kathode rays. Nature, v. 1370, n. 53, p. 298-299, 1896. Traduzido de um artigo previamente publicado em Paris Academy of Sciences, dez 1895.

PNHEIRO, B. C. S. @Descolonizando_saberes: mulheres negras na ciência. São Paulo: Livraria da Física, 2020. 71 p. (Coleção culturas, direitos humanos e diversidade na educação em ciências) 
SAITO, F. Revelando processos naturais por meio de instrumentos e outros aparatos científicos. In: BELTRAN, M. H. R.; SAITO, F.; TRINDADE, L. dos S. P. (Orgs). História da Ciência: Tópicos atuais 3. São Paulo: Livraria da Física, 2014. 230 p.

SASSERON, L. H.; CARVALHO, A. M. P. Construindo argumentação na sala de aula: a presença do ciclo argumentativo, os indicadores de Alfabetização Científica e o padrão de Toulmin. Ciência \& Educação, v. 17, n. 1, p. 97-114, 2011.

SCHMIEDECKE, W. G.; PORTO, P. A. Uma abordagem da história da energia nuclear para a formação de professores de física. Revista Brasileira de História da Ciência, v. 7, n. 2, p. 232-241, jul.-dez. 2014.

SCHWARTZ, G.; BISHOP, P. W. Moments of Discovery: The development of modern Science. New York: Basic Books, Inc, 1958. 1005 p. v. 2.

SERWAY, R. A.; JEWETT, J. W. Physics for Scientists and Engineers with Modern Physics. 9th edition. United States: Cengage Learning, 2014. 1616 p.

SMITH, G. E. J. J. Thomson and the electron, 1897-1899. In: BUCHWALD, J. Z.; WARWICK, A. (Ed.). Histories of the electron: the birth of microphysics. London: MIT Press, 2001. $514 \mathrm{p}$.

TEIXEIRA, E. S.; GRECA, I. M.; FREIRE JR, O. Uma revisão sistemática das pesquisas publicadas no Brasil sobre o uso didático de História e Filosofia da Ciência no ensino de Física. In: PEDUZZI, L. O. Q.; MARTINS, A. F. P.; FERREIRA, J. M. H. (Orgs.). Temas de História e Filosofia da Ciência no Ensino. Natal: EDUFRN, 2012. 372 p.

TIPlER, P. A.; LLEWELlyn, R. A. Física Moderna. 6. ed. Rio de Janeiro: Livros Técnicos e Científicos Editora Ltda, 2014. 490 p.

THOMSON, J. J. Cathode rays. Philosophical Magazine, v. 44, p. 293-316, 1897. Republicado em SCHWARTZ, G.; BISHOP, P. W. Moments of Discovery: The development of modern Science. New York: Basic Books, Inc, 1958. 1005 p. v. 2.

THOMSON, J. J. Conduction of electricity through gases. Cambridge: Cambridge University Press, 1903. 566 p. [Classic reprint series, Forgotten Books, 2012].

TOWNSEND, J. S. E. Electricity in gases. Oxford: Clarendon Press, 1915. 496 p. Disponível em: <https://archive.org/details/electricityinga00towngoog>. Acesso em: 03 abr. 2021. 
VASCONCELOS, S. S.; FORATO, T. C. M. Niels Bohr, espectroscopia e alguns modelos atômicos no começo do século XX: um episódio histórico para a formação de professores. Caderno Brasileiro de Ensino de Física, v. 35, n. 3, p. 851-887, dez. 2018.

VELOSO, G. L. F.; MENDONÇA, P. C. C.; MOZZER, N. B. Compreensões sobre natureza da ciência de uma licencianda em química a partir de suas reflexões sobre um estudo de caso histórico. Revista Ensaio, v. 22, e25329, p. 1-23, 2020.

WEINBERG, S. Para explicar o mundo: a descoberta da ciência moderna. São Paulo: Companhia das Letras, 2015. 494 p.

WEINBERG, S. The discovery of subatomic particles. Revised edition. Cambridge: Cambridge University Press, 2003. 206 p.

WHITTAKER, E. T. Theories of aether and electricity. Dublin: Longmans, Green, and Co., 1910. 475 p. [Classic reprint series, Forgotten Books, 2012]. 